\title{
Towards improving the identification of anterior cruciate ligament tears in primary point-of-care settings
}

\author{
Jackie L. Whittaker ${ }^{1,2,3^{*}}$, Michelle Chan ${ }^{4}$, Bo Pan ${ }^{5}$, Imran Hassan ${ }^{5}$, Terry Defreitas ${ }^{4,6}$, Catherine Hui ${ }^{4,7}$,
} Luciana Macedo ${ }^{8}$ and David Otto ${ }^{4,7}$

\begin{abstract}
Background: Only a small proportion of anterior cruciate ligament $(A C L)$ tears are diagnosed on initial healthcare consultation. Current clinical guidelines do not acknowledge that primary point-of-care practitioners rely more heavily on a clinical history than special clinical tests for diagnosis of an ACL tear. This research will assess the accuracy of combinations of patient-reported variables alone, and in combination with clinician-generated variables to identify an ACL tear as a preliminary step to designing a primary point-of-care clinical decision support tool.

Methods: Electronic medical records (EMRs) of individuals aged 15-45 years, with ICD-9 codes corresponding to a knee condition, and confirmed $\left(\mathrm{ACL}^{+}\right)$or denied $\left(\mathrm{ACL}^{-}\right)$first-time $\mathrm{ACL}$ tear seen at a University-based Clinic between 2014 and 2016 were eligible for inclusion. Demographics, relevant diagnostic indicators and ACL status based on orthopaedic surgeon assessment and/or MRI reports were manually extracted. Descriptive statistics calculated for all variables by ACL status. Univariate between group comparisons, clinician surveys $(n=17)$, availability of data and univariable logistic regression $(95 \% \mathrm{Cl})$ were used to select variables for inclusion into multivariable logistic regression models that assessed the odds $(95 \% \mathrm{Cl})$ of an ACL-tear based on patient-reported variables alone (consistent with primary point-of-care practice), or in combination with clinician-generated variables. Model performance was assessed by accuracy, sensitivity, specificity, positive and negative predictive values, and positive and negative likelihood ratios $(95 \% \mathrm{Cl})$.
\end{abstract}

Results: Of 1512 potentially relevant EMRs, 725 were included. Participant median age was 26 years (range 15-45), $48 \%$ were female and $60 \%$ had an ACL tear. A combination of patient-reported (age, sport-related injury, immediate swelling, family history of $\mathrm{ACL}$ tear) and clinician-generated (Lachman test result) variables were superior for $\mathrm{ACL}$ tear diagnosis [accuracy; 0.95 (90,98), sensitivity; $0.97(0.88,0.98)$, specificity; $0.95(0.82,0.99)$ ] compared to the patientreported variables alone [accuracy; 84\% (77,89), sensitivity; 0.60 (0.44,0.74), specificity; $0.95(0.89,0.98)]$.

(Continued on next page)

\footnotetext{
* Correspondence: jackie.whittaker@ubc.ca

'Department of Physical Therapy, Faculty of Medicine, University of British

Columbia, 2177 Westbrook Mall, Vancouver V6T 1Z3, Canada

${ }^{2}$ Arthritis Research Canada, Richmond, Canada

Full list of author information is available at the end of the article
}

(C) The Author(s). 2020 Open Access This article is licensed under a Creative Commons Attribution 4.0 International License, which permits use, sharing, adaptation, distribution and reproduction in any medium or format, as long as you give appropriate credit to the original author(s) and the source, provide a link to the Creative Commons licence, and indicate if changes were made. The images or other third party material in this article are included in the article's Creative Commons licence, unless indicated otherwise in a credit line to the material. If material is not included in the article's Creative Commons licence and your intended use is not permitted by statutory regulation or exceeds the permitted use, you will need to obtain permission directly from the copyright holder. To view a copy of this licence, visit http://creativecommons.org/licenses/by/4.0/. The Creative Commons Public Domain Dedication waiver (http://creativecommons.org/publicdomain/zero/1.0/) applies to the data made available in this article, unless otherwise stated in a credit line to the data. 
(Continued from previous page)

Conclusions: A high proportion of individuals without an ACL tear can be accurately identified by considering patient-reported age, injury setting, immediate swelling and family history of ACL tear. These findings directly inform the development of a clinical decision support tool to facilitate timely and accurate ACL tear diagnosis in primary care settings.

Keywords: Diagnosis, Family medicine, Knee trauma, Physical therapy

\section{Background}

Anterior cruciate ligament (ACL) tears are common in persons between the ages of 15-30 years, with an overall incidence estimated at 30 to 80 injuries per 100,000 persons (general population) [1-4]. These injuries most commonly occur during sport and recreational activities that involve frequent cutting, pivoting and jumping $[3,5,6]$. ACL tears are associated with reduced function [7-9], physical inactivity, increased risk of further injury [10], and future obesity [11] and/or osteoarthritis (OA) [12-14].

Although there is controversy regarding the need for, and timing of reconstructive surgery following an ACL tear [15], it is well established that an early and accurate diagnosis is vital to ensuring timely and appropriate treatment, which in turn improves both immediate (e.g., return to work, return to sport) and long-term (e.g., physical activity) outcomes [16]. Current clinical guidelines for full-thickness ACL tear diagnosis recommend obtaining a relevant history and performing a thorough clinical examination [17, 18]. Typically, a diagnosis is achieved by considering the mechanism of injury, immediacy of symptoms, pain location, observation, palpation, and outcome of special clinical tests [3, 19-21]. Experienced practitioners express confidence in diagnosing ACL tears without the need for diagnostic imaging which many consider to be a superfluous expense [22], and due to a lack of accessibility in some health systems, a preventable barrier to treatment [23].

Previous investigations have reported the diagnostic accuracy of a clinical examination for identifying a full-thickness ACL tear as good (i.e., sensitivity $0.77-0.99$, specificity of $0.73-1.00$ ) when performed by a healthcare practitioner with advanced orthopaedic training $[21,23]$. Not surprisingly, the diagnostic accuracy of a clinical examination varies between orthopedic surgeons (94\% accuracy) and primary care physicians (62\% accuracy), with surgeons relying on both the clinical history and physical examination, and primary care physicians relying more heavily on the clinical history alone [24]. Differences in the weighting of clinical examination components for ACL tear diagnosis between practice settings likely reflect disparities in time between injury and examination, proportion of caseload comprised of acute knee injuries and confidence in performing clinical tests, amongst other factors.
Only 6.8 to $28.2 \%$ of ACL tears are diagnosed on initial healthcare consultation, with many patients waiting months for a correct diagnosis [3, 25-29]. Missed or falsely diagnosed ACL tears may result in delayed or misdirected rehabilitation, physician, and specialist visits and diagnostic imaging. At an individual level, misdiagnosis can lead to reduced mobility and knee confidence, physical inactivity, delayed return to activity (e.g., work or sport/recreation) and an increased risk of subsequent injuries, (e.g., meniscus tear) $[3,30,31]$ and disease (e.g., post-traumatic OA) [32]. To facilitate timely and appropriate treatment, while minimizing individual patient and healthcare system burden, it is essential that primary point-of-care healthcare practitioners (e.g., emergency room physicians, family medicine physicians, physiotherapists) can accurately diagnose a fullthickness ACL tear early after injury.

Although the clinometric properties of individual diagnostic tests for full-thickness ACL tears [33, 34], and the diagnostic value of common clinical signs and symptoms [17] have been examined, previous investigations suffer from methodological limitations (i.e., small sample sizes), risk of selection bias [20, 23, 24, 28, 35-39] and have not acknowledged differences in the approach to ACL tear diagnosis between primary point-of-care practitioners and those with advanced orthopaedic training. Currently, there is no consensus about which combination of demographic characteristic(s), or clinical history and/or examination component(s) are the most valuable for the inclusion or exclusion of an ACL tear diagnosis that considers differences in practice patterns and competencies of primary point-of-care practitioners. A better understanding of the best combination of patientreported variables, independent and in combination with clinician-generated variables for diagnosis of a fullthickness ACL tear could inform the development and evaluation of a primary point-of-care clinical decision tool aimed at facilitating early and accurate diagnosis. The primary objective of this study is to develop and internally validate two preliminary statistical models aimed at predicting full-thickness ACL tears based upon the best combination of patient-reported variables only or in combination with clinician-generated variables. We hypothesize that both statistical models will hold diagnostic value. 


\section{Methods}

\section{Study design and setting}

This is a retrospective cohort study of the Electronic Medical Records (EMRs) of all patients, aged 15 to 45 years, who saw one of 11 primary care sport and exercise medicine primary care physicians or four orthopaedic surgeons at a multidisciplinary University-based community Sports Medicine Clinic for a knee condition between January 1, 2014 and June 30, 2016. Referrals to this clinic are from general practice physicians and physiotherapists. This study is reported as recommended by the Standards for Reporting Diagnostic Accuracy Studies 2015 (STARD) [40].

\section{Data source}

Eligible individual EMRs were identified through a systematic search of the clinic's EMR system (৫HealthQuest). All records with a pre-determined International Classification of Disease-9 (ICD-9) code corresponding to a knee condition (see Additional file 1) with a confirmed or denied first-time full-thickness ACL tear were included. EMRs were excluded if the knee injury occurred prior to the pre-established study dates, represented a chronic ACL deficiency or re-tear of the ACL, or if the recorded diagnosis was knee OA. Prior to the study it was determined that a sample of 460 individual patient EMRs would provide appropriate statistical power $(1-\beta=0.8)$ based on 10 events per variable [41] for the outcome of interest (ACL tear), accounting for collinearity and assuming 55\% EMR completion, 45\% of completed EMRs represent individuals with ACL tears, and a predictive model $(\alpha=0.05)$ of 10 independent variables.

\section{Reference standard}

ACL tear diagnosis was based on a composite reference standard consisting of orthopaedic surgeon diagnosis and/or MRI findings to minimize misclassification bias. Diagnoses were dichotomized into full thickness ACL tear $\left(\mathrm{ACL}^{+}\right.$; Lachman grade III) and no full-thickness ACL tear ( $\mathrm{ACL}^{-}$; Lachman grade 0, I and II). Given that the sensitivity of clinical examination and MRI for identifying an ACL tear are $0.77-0.99[21,23]$ and $0.84-0.90$ [42] respectively, there may be limitations to this criterion. However, as not all patients with an intra-articular knee injury require surgery, this combination was the most viable for identifying true negatives and false positives while minimizing verification bias.

\section{Procedures}

Relevant data were manually extracted from the physician and/or surgeon chart notes, letters, diagnostic imaging and surgical reports contained within eligible EMRs. These data were compiled by research personnel and then audited for accuracy by one research team member (MC) using a custom designed data extraction tool (REDCap v6.17.2,@2017 Vanderbilt University). Extracted data included: 1) demographic characteristics (i.e., age, sex, height, weight, sport at time of injury if applicable), 2) injury details (i.e., date of injury, time since injury, time to diagnosis), 3) diagnostic details (i.e., ICD9 code, surgeon diagnosis, diagnostic imaging study type, diagnostic imaging referring professional, diagnostic imaging findings), and 4) potential ACL tear diagnostic indicators (see Table 1).

Potential diagnostic indicators (i.e., mechanism of injury, clinical history and examination elements) were identified through a search of relevant literature and an anonymous healthcare practitioner survey (Additional file 2). Specifically, healthcare practitioners and consultants (i.e., physiotherapists, primary care sport and exercise medicine physicians and orthopaedic surgeons) were provided with an anonymous link to a short survey which asked them to identify and then rank what demographic characteristic(s), and/or clinical history and examination component(s) they felt were the most valuable for diagnosing a fullthickness ACL tear. Respondents ranked items within categories (i.e., patient characteristics, mechanism of injury, patient-reported symptoms at time of injury, clinical history responses, and clinical examination tests) in order of perceived importance. Potential diagnostic indicators that were ranked in the top tertile by at least one third of respondents were included in the data extraction tool.

\section{Statistical analysis}

Analyses were performed using STATA® (v14.2, Collage Station, Texas, USA), R@ 3.4.0. (Vienna, Austria) and SAS $\odot$ 9.4 (Cary, NC, USA). Descriptive statistics including mean $(95 \% \mathrm{CI})$, median (range), or proportion (exact $95 \% \mathrm{CI}$ ) were used to compare characteristics (i.e., age and sex) between patients represented by EMRs that did and did not meet the study inclusion criteria. For included EMR's, missing data were identified and descriptive statistics including mean $(95 \% \mathrm{CI})$, median (range) or proportion (exact 95\%CI) were reported for all participant characteristics, potential diagnostic indicators and treatment pathway information variables by ACL status (study group) as appropriate. Univariable analyses (i.e., independent t-tests, Wilcoxon rank sum test, chi-square or Fisher's test) were used to compare participant characteristics, potential diagnostic indicators and treatment pathway information by study group, as appropriate, accounting for multiple comparisons $(p=0.05 / 43=0.001)$. Assumptions of statistical tests were satisfied and the normality of continuous variable was tested with Normal Quantile-Quantile plots. The results of the healthcare practitioner survey were tabulated. Univariable logistic regression [odds ratio (OR), 95\% CI] assessing the odds of an ACL tear were performed for selected variables 
Table 1 Summary of potential diagnostic indicators extracted from electronic medical records

\begin{tabular}{ll}
\hline Clinical History - Mechanism of Injury & contact or non-contact \\
Clinical History - Time of Injury & hyperextension, hyperflexion, plant/pivot, varus or valgus motion \\
& heard or felt a 'pop' \\
& immediate $(<30$ min $)$ or delayed pain \\
& immediate $(<4 \mathrm{~h})$ or delayed swelling \\
& inability to return to current activity \\
Clinical Knee Examination & inability to weight bear \\
& flexion and extension range of motion \\
& Lachman, Anterior Drawer and Pivot Shift test result \\
& valgus and varus stress test result \\
& Posterior Drawer test result \\
McMurray, Apprehension test result & presence and location of joint line pain \\
& presence and location of pain with palpation
\end{tabular}

that significantly differed between study groups on univariable analyses (i.e., $p$-value $<0.001$ ) taking into consideration data availability and whether or not they were considered relevant based on the practitioner survey or literature review.

Multivariable logistic regression models were conducted with all prioritized variables and odds ratios (OR; $95 \% \mathrm{CI}$ ) for each variable in the final regression models were calculated. Items prioritized for inclusion into multivariable logistic regression models included the most promising patient-reported and clinician-generated predictors based on univariable logistic regression $(p<$ $0.10)$. An 'a priori' decision was made to develop two multivariable logistic regression models for identifying an ACL tear. The first model included patient-reported predictors only to be consistent with primary point-ofcare practice settings, while the second model included patient-reported and clinician-generated predictors. All assumptions for regression analyses were assessed. Multivariable models were built on a training set (random $70 \%$ of data) and evaluated with a test set (remaining $30 \%$ of data). To assess the performance of the models, accuracy rate $(95 \% \mathrm{CI})$, the area under (AUC) the receiver-operating characteristic (ROC) curve, sensitivity $(95 \% \mathrm{CI})$, specificity $(95 \% \mathrm{CI})$, positive and negative predictive values $(95 \% \mathrm{CI})$ and positive $(\mathrm{LR}+)$ and negative (LR-) likelihood ratios $(95 \% \mathrm{CI})$ were calculated.

\section{Results}

Of 1512 eligible individual EMRs, 725 met inclusion criteria (Fig. 1). Reasons for excluding EMRs included: no physician data sharing agreement $(n=133)$; injury occurred prior to January 2014 $(n=373)$; chronic ACL deficiency $(n=114)$; ACL re-tear $(n=37)$; osteoarthritis $(n=68)$; and mis-coding (i.e., a non-knee injury being coded as a knee injury) ( $n=76)$. There was no difference in sex (included; $47.7 \%$ female, 95\%CI 44.1, 51.4: excluded; $42.4 \%$ female, $95 \%$ CI 39.0 , 45.9) or age (included; median age 26 years, range $15-45$ : excluded; median age 29 years, range 15-45) between the patients whose EMRs were included and those that were excluded.

The demographic characteristics and availability of clinical criterion standard data of all participants' records that met inclusion criteria $(n=725)$ are presented in Table 2 . The majority of participants had undergone an MRI (89.8\%), 68.1\% had been assessed by an orthopaedic surgeon, and $39.3 \%$ had undergone surgery (i.e., arthroscopy or ACL reconstruction).

Of the 725 EMRs that met the inclusion criteria for the study, $436(60.1 \%)$ represented a patient with a fullthickness $\mathrm{ACL}$ tear $\left(\mathrm{ACL}^{+}\right)$based upon the reference standard. A summary of demographic characteristics, potential diagnostic variables, and treatment pathway information by ACL status is presented in Table 3. Sex, age and body mass index did not differ between study groups. Although no single diagnostic indicator emerged, on average a greater proportion $(p<0.001)$ of the $\mathrm{ACL}^{+}$study group reported a non-contact or plant-pivot mechanism of injury; a 'popping sensation', pain, immediate swelling, instability or inability to continue their activity at the time of injury; instability and an inability to return to activity at some point since the injury, and a family history of ACL tear compared to the $\mathrm{ACL}^{-}$group. On clinical exam, a greater portion of those in the $\mathrm{ACL}^{+}$group demonstrated a positive Lachman, positive pivot shift, or positive posterior drawer test compared to the $\mathrm{ACL}^{-}$group. 


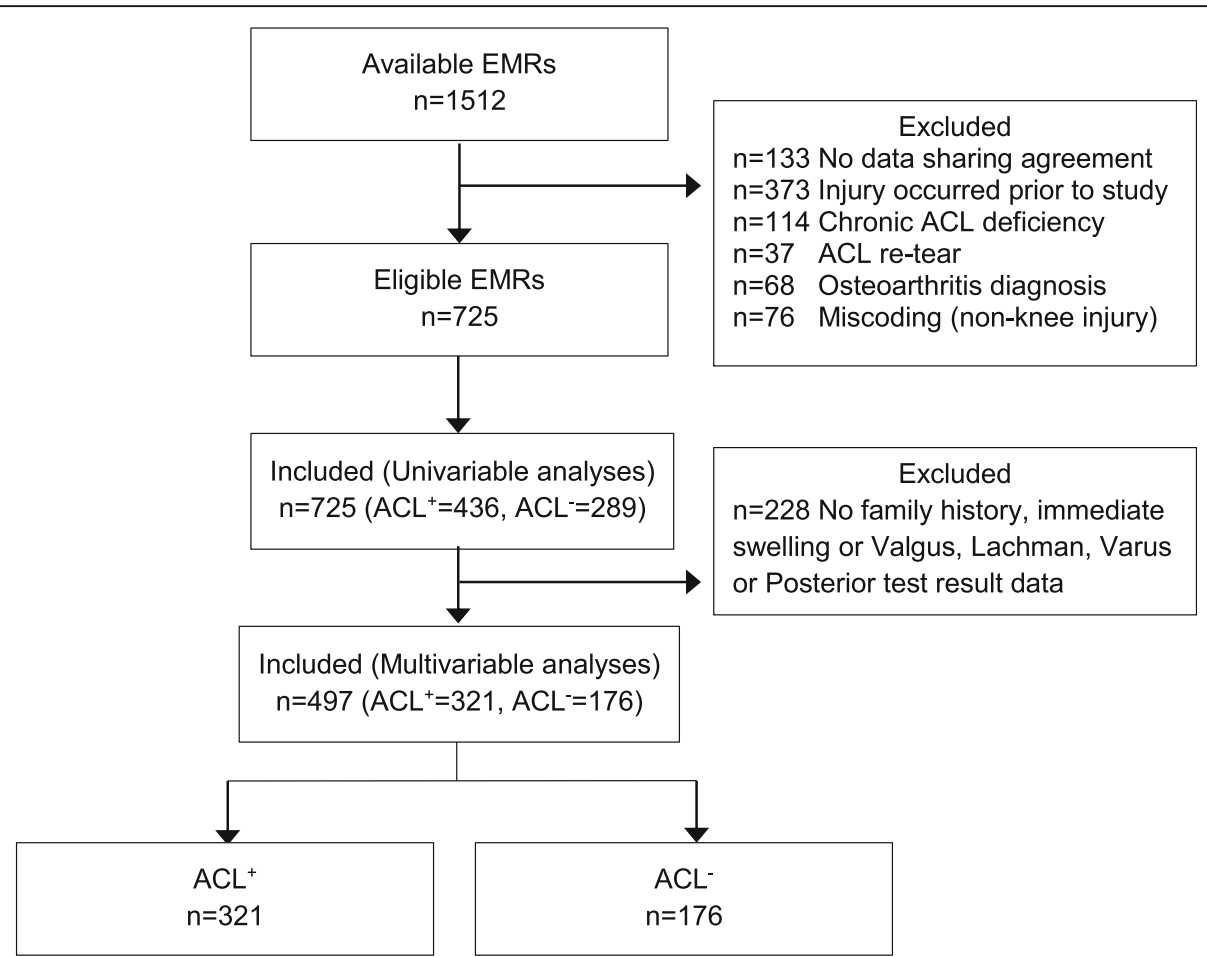

Fig. 1 STARD diagram of the flow of Electronic Medical Records through the study

The healthcare practitioner survey was completed by 17 clinicians (8 physiotherapists, 6 primary care sport and exercise medicine physicians, and 3 orthopaedic surgeons) with a median (minimum-maximum) of 11 (443) years of clinical experience. Across respondents, the most commonly selected potential diagnostic criteria for

Table 2 Participant characteristics and reference standard availability $(n=725)$

\begin{tabular}{|c|c|}
\hline Variable & Summary Statistic \\
\hline \multicolumn{2}{|l|}{ Participant Characteristic } \\
\hline Sex: total (\%) female & $346(47.7)$ \\
\hline Age: years & $26(15-45)$ \\
\hline Height: $\mathrm{cm}$ & $173(151-199)$ \\
\hline Weight: kg & $77.6(43.0-152.4)$ \\
\hline BMI: kg/m² & $25.5(17.5-51.0)$ \\
\hline Not sport-related injury: total (\%) & $97(13.4)$ \\
\hline Sport: total (\%) soccer & $176(24.3)$ \\
\hline Time from injury to consultation: days & $176(1-798)$ \\
\hline \multicolumn{2}{|l|}{ Reference Standard } \\
\hline$M R I^{\circ}:$ total $(\%)$ & $651(89.8)$ \\
\hline Orthopaedic surgeon exam: total (\%) & $494(68.1)$ \\
\hline Surgery: total (\%) & $285(39.3)$ \\
\hline
\end{tabular}

an ACL tear included: 1) positive Lachman test (65\% of respondents ranked as the most important cliniciangenerated diagnostic criteria), 2) hearing or feeling a 'pop' at the time of injury (59\% of respondents ranked as most important time of injury diagnostic criteria), 3) patient-reported knee instability since the injury $(59 \%$ ranked as the most important clinical history diagnostic criteria), 4) plant/pivot mechanism of injury (53\% ranked as the most important mechanism of injury diagnostic criteria) and, 5) age less than 25 years (47\% ranked as the most important participant characteristic diagnostic criteria).

Table 4 summarizes the variables prioritized for univariable logistic regression by descending rank order based on the cumulative number of EMRs with available data by study group $\left(\mathrm{ACL}^{+}\right.$and $\left.\mathrm{ACL}^{-}\right)$. In keeping with our sample size calculation, univariable logistic regression was performed on 497 (68.6\%) EMRs (321 $\mathrm{ACL}^{+}$ and $176 \mathrm{ACL}^{-}$) containing complete data for both prioritized (age, sex, sport-related injury, Lachman test result, posterior drawer test result, family history of ACL tear and immediate swelling at the time of injury) and incidental (i.e., variables available in the data that did not meet selection criteria) variables (time between injury and assessment, valgus stress test result, varus test result). Despite being significant on univariable analyses, or ranking high on healthcare practitioner survey, feeling or hearing a 'pop' at the time of injury, mechanism of 
Table 3 Demographic characteristics, potential diagnostic variables and treatment pathway by ACL status $(n=725)$

\begin{tabular}{|c|c|c|c|c|}
\hline Variable & $\begin{array}{l}\mathrm{ACL}^{-} \\
n=289\end{array}$ & $\begin{array}{l}\mathrm{ACL}^{+} \\
n=436\end{array}$ & $P$-value & Records Available \\
\hline \multicolumn{5}{|l|}{ Participant Characteristic } \\
\hline Sex: total (\%) female & $133(46.0)$ & $213(48.9)$ & 0.455 & 725 \\
\hline Age: median years (min-max) & $26(15-46)$ & $26(15-45)$ & 0.989 & 725 \\
\hline Height: median cm (min-max) & $176.4(155-197)$ & $172.0(151-199)$ & $<0.001^{*}$ & 510 \\
\hline Weight: median kg (min-max) & $81.0(48.4-152.4)$ & $76(43.0-149.3)$ & 0.003 & 510 \\
\hline BMI: median kg/m² (min-max) & $25.8(18.4-45.4)$ & $25.4(17.5-51.0)$ & 0.193 & 510 \\
\hline Not sport-related: total (\%) & $64(22.1)$ & $33(7.6)$ & $<0.001^{*}$ & 725 \\
\hline Sport: total (\%) soccer & $47(16.3)$ & $129(29.6)$ & $<0.001^{*}$ & 725 \\
\hline \multicolumn{5}{|l|}{ Mechanism of Injury } \\
\hline Non-contact: \% (95\%Cl) & $72.4(66.0,78.0)$ & $84.2(80.4,87.4)$ & $<0.001^{*}$ & 632 \\
\hline Hyperextension: \% (95\%Cl) & $10.8(6.7,17.0)$ & $11.8(8.5,16.2)$ & 0.759 & 420 \\
\hline Hyperflexion: \% (95\%Cl) & $6.1(3.2,11.3)$ & $1.8(0.8,4.4)$ & 0.021 & 420 \\
\hline Plant/pivot: \% (95\%Cl) & $17.7(12.4,24.7)$ & $52.0(46.1,57.8)$ & $<0.001^{*}$ & 431 \\
\hline Valgus: \% (95\%Cl) & $23.2(17.1,30.6)$ & $27.7(22.7,33.3)$ & 0.313 & 422 \\
\hline Varus: \% (95\%Cl) & $5.3(2.7,10.3)$ & $7.3(4.7,11.1)$ & 0.436 & 424 \\
\hline \multicolumn{5}{|l|}{ Time of Injury } \\
\hline Pop: \% (95\%Cl) & $47.3(40.5,54.2)$ & $83.3(79.1,86.9)$ & $<0.001^{*}$ & 559 \\
\hline Pain: \% (95\%Cl) & $65.3(58.1,72.0)$ & $97.8(95.3,99.0)$ & $<0.001^{*}$ & 461 \\
\hline Immediate swelling: \% (95\%Cl) & $57.1(50.8,63.2)$ & $91.8(88.7,94.1)$ & $<0.001^{*}$ & 648 \\
\hline Instability: \% (95\%Cl) & $55.4(47.2,63.3$ & $97.5(95.1,98.7)$ & $<0.001^{*}$ & 468 \\
\hline Locking: \% (95\%Cl) & $21.3(13.5,31.8)$ & $57.9(34.8,78.0)$ & 0.003 & 99 \\
\hline Catching: \% (95\%Cl) & $1.6(0.2,10.7)$ & $12.5(1.4,58.2)$ & 0.211 & 72 \\
\hline Inability to continue activity: $\%(95 \% \mathrm{Cl})$ & $51.8(44.2,59.2)$ & $93.2(89.7,95.7)$ & $<0.001^{*}$ & 452 \\
\hline \multicolumn{5}{|l|}{ Clinical History (since the injury) } \\
\hline Delayed pain: \% (95\%Cl) & $3.4(1.5,7.4)$ & $1.4(0.5,3.8)$ & 0.147 & 454 \\
\hline Delayed swelling: \% (95\%Cl) & $17.4(13.1,22.8)$ & $6.5(4.5,9.4)$ & $<0.001^{*}$ & 641 \\
\hline Pain: \% (95\%Cl) & 100 & 100 & - & 668 \\
\hline Swelling: \% (95\%Cl) & $96.7(90.2,98.9)$ & $99.5(97.8,99.9)$ & $0.056^{*}$ & 457 \\
\hline Instability: \% (95\%Cl) & $75.4(69.1,80.6)$ & $98.8(97.2,99.5)$ & $<0.001^{*}$ & 648 \\
\hline Locking: \% (95\%Cl) & $32.0(25.2,39.8)$ & $45.6(37.4,54.1)$ & 0.017 & 295 \\
\hline Catching: \% (95\%Cl) & $38.9(28.2,50.7)$ & $33.3(21.6,47.5)$ & 0.529 & 123 \\
\hline Inability to weight bear: \% $(95 \% \mathrm{Cl})$ & $93.0(82.5,97.4)$ & $99.4(95.8,99.9)$ & 0.016 & 222 \\
\hline Inability to return to activity: $\%(95 \% \mathrm{Cl})$ & $90.6(85.3,94.0)$ & 100 & $<0.001^{*}$ & 546 \\
\hline Family history of ACL tear: \% (95\%Cl) & $3.3(1.6,6.4)$ & $22.8(18.8,27.4)$ & $<0.001^{*}$ & 609 \\
\hline \multicolumn{5}{|l|}{ Clinical Examination } \\
\hline Positive Lachman: \% (95\%Cl) & $9.6(6.6,13.8)$ & $91.3(88.2,93.6)$ & $<0.001^{*}$ & 695 \\
\hline Positive Pivot shift: \% (95\%Cl) & $3.7(1.8,7.1)$ & $87.2(83.3,90.3)$ & $<0.001^{*}$ & 570 \\
\hline Positive Anterior drawer: \% $(95 \% \mathrm{Cl})$ & $6.1(3.6,10.0)$ & $86.6(81.2,90.7)$ & $<0.001^{*}$ & 433 \\
\hline Positive Posterior drawer: \% (95\%Cl) & $4.9(2.8,8.4)$ & $1.2(0.5,0.3)$ & $<0.001^{*}$ & 649 \\
\hline Positive Valgus stress: \% (95\%Cl) & $9.7(6.7,13.8)$ & $7.4(5.2,10.3)$ & 0.284 & 690 \\
\hline Positive Varus stress: \% (95\%Cl) & $1.2(0.4,3.6)$ & $0.1(0.04,2.6)$ & 0.542 & 664 \\
\hline \multicolumn{5}{|l|}{ Care Pathway } \\
\hline X-ray: total (\%) & $240(83.0)$ & $372(85.3)$ & 0.41 & 725 \\
\hline
\end{tabular}


Table 3 Demographic characteristics, potential diagnostic variables and treatment pathway by ACL status ( $n=725)$ (Continued)

\begin{tabular}{lllll}
\hline Variable & $\begin{array}{l}\mathrm{ACL}^{-} \\
n=289\end{array}$ & $\begin{array}{l}\mathrm{ACL}^{+} \\
n=436\end{array}$ & $\begin{array}{c}P \text {-value } \\
\text { Records Available }\end{array}$ \\
\hline MRl: total (\%) & $279(96.5)$ & $356(81.7)$ & $<0.001^{*}$ & 725 \\
Orthopaedic surgeon exam: total (\%) & $103(35.6)$ & $391(89.7)$ & $<0.001^{*}$ & 725 \\
Surgery: total (\%) & $27(9.3)$ & $258(59.2)$ & $<0.001^{*}$ & 725 \\
Injury to consultation: median days (min-max) & $126(1-730)$ & $176(1-798)$ & 0.0246 & 725 \\
Injury to MRl: median days (min-max) & $113(2-804)$ & $52(1-535)$ & $<0.001^{*}$ & 725 \\
Injury to surgeon: median days (min-max) & $186(1-806)$ & $198(10-806)$ & 0.561 & 725 \\
Injury to surgery: median days (min-max) & $192(15-988)$ & $308(19-959)$ & 0.04 & 725 \\
\hline
\end{tabular}

Values represent number (\%) unless otherwise stated

$A C L$ Anterior Cruciate Ligament, $A C L^{-} \mathrm{ACL}$ intact, $A C L^{+} \mathrm{ACL}$ full-thickness tear, $A K I C$ Acute knee injury clinic, $B M I$ Body Mass Index, $C l \mathrm{confidence}$ interval, $\mathrm{Cm}$ centimeters, $\mathrm{kg}$ kilograms, $m$ meters, MRI Magnetic Resonance Imaging

*Statistically significant at $a<0.001$

injury, patient-reported knee instability since the injury, or anterior drawer and pivot shift test result were inconsistently reported across EMRs and were not included due to a lack of data.

The results of univariable logistic regression models assessing the relationship between potential individual predictors and ACL status are presented in Table 5. Variables that were significantly associated with ACL tear at $p<0.1$ included age $(p=0.001)$, sport-related injury or trauma $(p=0.094)$, family history of ACL tear $(p=$ $0.032)$, immediate swelling at time of injury $(p=0.001)$ and Lachman test result $(p<0.001)$.

The results of the multivariable logistic regression models are summarized in Table 6. The first model included patient-reported variables (age, sport-related injury, immediate swelling, and family history ACL tear) only, while the second model included a combination of patient-reported (age, sport-related injury, immediate swelling, and family history ACL tear) and cliniciangenerated variables (Lachman test result). In the patientreported model older age, sport-related injury, immediate swelling, and family history of ACL tear was found to be significantly associated with a full-thickness ACL tear diagnosis. When the Lachman test result was considered alongside the patient-reported variables in the combined model, only older age, immediate swelling, and a positive Lachman test result were significantly associated with the diagnosis of a full-thickness ACL tear.

Table 4 Variables prioritized for univariable logistic regression based on univariable statistics, practitioner survey, literature review and data availability by study group

\begin{tabular}{|c|c|c|c|c|c|}
\hline \multicolumn{2}{|c|}{ Prioritized Variable } & \multirow[t]{2}{*}{ Incidental Variable ${ }^{+}$} & \multirow{2}{*}{$\begin{array}{l}\text { Total EMRs } \\
725\end{array}$} & \multirow{2}{*}{$\begin{array}{l}\mathrm{ACL}^{+} \\
\mathrm{EMRs} \\
444\end{array}$} & \multirow{2}{*}{$\begin{array}{l}\mathrm{ACL}^{-} \\
\text {EMRs } \\
281\end{array}$} \\
\hline Included & Age & & & & \\
\hline & Sex & & 725 & 444 & 281 \\
\hline & \multirow[t]{3}{*}{ Sport-related injury } & & 725 & 444 & 281 \\
\hline & & Time between injury and consultation & 725 & 444 & 281 \\
\hline & & Valgus stress test result & 690 & 427 & 263 \\
\hline & \multirow[t]{2}{*}{ Lachman test result } & & 672 & 418 & 254 \\
\hline & & Varus stress test result & 647 & 406 & 241 \\
\hline & Posterior drawer test result & & 627 & 397 & 230 \\
\hline & Family history of $A C L$ tear & & 550 & 343 & 207 \\
\hline & Immediate swelling & & 497 & 321 & 176 \\
\hline \multirow[t]{5}{*}{ Excluded } & History of knee instability & & 452 & 312 & 140 \\
\hline & Pivot shift test result & & 400 & 270 & 130 \\
\hline & Contact vs. non-contact & & 352 & 263 & 89 \\
\hline & Pop at time of injury & & 305 & 230 & 75 \\
\hline & History of inability to RTS & & 261 & 206 & 55 \\
\hline
\end{tabular}

${ }^{+}$Incidental variable $=$a variable available in the dataset despite not being prioritized based on univariate between group comparison, practitioner survey or literature review

$A C L$ Anterior Cruciate Ligament, $A C L^{+} \mathrm{ACL}$ full-thickness tear, $A C L^{-} \mathrm{ACL}$ intact, EMRs electronic medical records, $R T S$ return to sport 
Table 5 Univariable logistic regression models $\left(n=497, \mathrm{ACL}^{+}=316, \mathrm{ACL}^{-}=181\right)$ assessing in the odds (95\%Cl) of an $\mathrm{ACL}$ tear

\begin{tabular}{|c|c|c|c|c|}
\hline Variable & Reference & Estimate (SE) & OR $(95 \% \mathrm{Cl})$ & $P$-value \\
\hline Age (years) & - & $0.08(0.03)$ & $1.08(1.03,1.14)$ & 0.001 \\
\hline Sex (male/female) & Male & $-0.21(0.21)$ & $0.66(0.29,1.47)$ & 0.306 \\
\hline Sport-related injury (sport/ non-sport) & Sport & $0.54(0.32)$ & $2.97(0.83,10.60)$ & 0.094 \\
\hline Time between injury and consultation (days) & - & $-0.0005(0.001)$ & $1.00(0.99,1.00)$ & 0.762 \\
\hline Valgus stress test $(+/-)$ & + & $-0.19(0.46)$ & $0.68(0.11,4.20)$ & 0.679 \\
\hline Lachman test result (+/-) & + & $2.60(0.22)$ & $181.99(75.73,437.31)$ & $<0.001$ \\
\hline Varus stress test $(+/-)$ & + & $6.09(586.8)$ & $>999.99(<0.001,>999.99)$ & 0.992 \\
\hline Posterior drawer test $(+/-)$ & + & $0.14(0.54)$ & $1.32(0.16,11.06)$ & 0.796 \\
\hline Family history (yes/no) & Yes & $0.76(0.35)$ & $4.55(1.14,18.15)$ & 0.032 \\
\hline Immediate swelling (yes/no) & Yes & $0.81(0.25)$ & $5.02(1.92,13.14)$ & 0.001 \\
\hline
\end{tabular}

$A C L$ Anterior Cruciate Ligament, $A C L^{+} \mathrm{ACL}$ full-thickness tear, $A C L^{-} \mathrm{ACL}$ intact, $S E$ standard error, $O R$ odds ratio, $C l$ confidence interval, $+=$ positive test result, $-=$ negative test result

Model performance based on a test set (random 30\% of data) is summarized in Table 7. It is interesting to note that the performance of the Lachman test alone was comparable to the combined patient-reported and clinician-generated variable model [accuracy rate $94.0 \%$ (95\%CI 88.9,97.2), AUC (0.94), sensitivity 0.94 (95\%CI $0.91,0.99)$, specificity $(0.94 \quad(95 \% \mathrm{CI} 0.76,0.96)$, positive predictive value $(0.94$ ( $95 \% \mathrm{CI} 0.88,0.98)$, negative predictive value (0.94 $(95 \% \mathrm{CI} 0.82,0.99), \mathrm{LR}+$ of 8.1 (95\% CI $3.8,17.1)$, LR- of $0.03(95 \%$ CI $0.01,0.10)]$.

\section{Discussion}

To the best of our knowledge this is the first study to assess the accuracy of combinations of patient-reported and clinician-generated variables to identify a first-time ACL tear that considers differences in practice patterns and competencies of primary point-of-care practitioners. Our findings demonstrate that a combination of patientreported and clinician-generated variables, or Lachman test alone, are superior for detecting a full-thickness
ACL tear compared to patient-reported variables alone. Specifically, increasing age, immediate swelling and Lachman test result accurately identified $95 \%$ of firsttime ACL tears, the Lachman test along accurately identified $94 \%$ of first-time ACL tears, while a combination of increasing age, sport-related trauma, immediate swelling, and family history of an ACL tear accurately identified $84 \%$ of tears. These accuracy rates are higher than those previously reported [35] and have direct implications for clinical decision support tool development for use in primary point-of-care clinical practice settings.

\section{Building from previous investigations}

By leveraging EMR data over a two-year period we were able to include a large sample of patients with a wide variation of knee conditions, age and time since injury. Similar to previous investigators [33-35, 43], we have demonstrated that a combination of clinical history and examination variables is diagnostically superior to individual elements $[24,35,39]$, and that immediate swelling

Table 6 Multivariable logistic regression models (based on training data)

\begin{tabular}{|c|c|c|c|c|c|c|c|}
\hline \multirow[t]{2}{*}{ Variable } & \multirow[t]{2}{*}{ Condition } & \multicolumn{3}{|c|}{ Model 1 (Patient-reported only) } & \multicolumn{3}{|c|}{ Model 2 (Patient-reported and Clinician-generated) } \\
\hline & & Estimate (SE) & OR $(95 \% \mathrm{Cl})$ & $p$-value & Estimate (SE) & OR $(95 \% \mathrm{Cl})$ & $p$-value \\
\hline Age & Year & $0.047(0.018)$ & $1.05(1.01 .1 .09)$ & $0.007^{*}$ & $0.059(0.028)$ & $1.06(1.00,1.12)$ & $0.034^{*}$ \\
\hline \multirow[t]{2}{*}{ Sport-related } & Sport & $1.261(0.414)$ & $3.53(1.57,7.93)$ & $0.002^{*}$ & $0.081(0.701)$ & $2.24(0.57,8.85)$ & 0.250 \\
\hline & Non-sport & Reference & & & Reference & & \\
\hline \multirow[t]{2}{*}{ Family history } & Yes & $2.601(0.616)$ & $13.47(4.03,45.06)$ & $<0.001^{*}$ & $1.021(0.847)$ & $2.78(0.53,14.62)$ & 0.228 \\
\hline & No & Reference & & & Reference & & \\
\hline \multirow[t]{2}{*}{ Immediate swelling } & Yes & $2.532(0.351)$ & $12.58(6.32,25.04)$ & $<0.001^{*}$ & $1.212(0.543)$ & $3.36(1.16,9.74)$ & $0.026^{*}$ \\
\hline & No & Reference & & & Reference & & \\
\hline \multirow[t]{2}{*}{ Lachman test result } & Positive & - & - & - & $5.038(0.498)$ & $154.17(58.04,409.49)$ & $<0.001^{*}$ \\
\hline & Negative & - & - & - & Reference & & \\
\hline
\end{tabular}

$A C L$ Anterior Cruciate Ligament, SE standard error, OR odds ratio, $C I$ confidence interval ${ }^{*} p<0.05$ 
Table 7 Multivariable logistic regression model performance (based on test set)

\begin{tabular}{lll}
\hline Performance Measure & $\begin{array}{l}\text { Model 1 } \\
\text { (Patient-reported only) }\end{array}$ & $\begin{array}{l}\text { Model 2 } \\
\text { (Patient-reported and Clinician-generated) }\end{array}$ \\
\hline Accuracy rate $(\% ; 95 \% \mathrm{Cl})$ & $84.0(77.1,89.5)$ & $94.7(89.8,97.7)$ \\
AUC score & 0.86 & 0.97 \\
Sensitivity $(95 \% \mathrm{Cl})$ & $0.59(0.44,0.74)$ & $0.94(0.88,0.98)$ \\
Specificity $(95 \% \mathrm{Cl})$ & $0.95(0.89,0.98)$ & $0.95(0.82,0.99)$ \\
Positive Predictive Value $(95 \% \mathrm{Cl})$ & $0.95(0.89,0.98)$ & $0.95(0.82,0.99)$ \\
Negative Predictive Value $(95 \% \mathrm{Cl})$ & $0.60(0.44,0.74)$ & $0.94(0.82,0.99)$ \\
Positive Likelihood Ratio $(95 \% \mathrm{Cl})$ & $5.53(2.46,12.44)$ & $9.51(4.14,21.84)$ \\
Negative Likelihood Ratio $(95 \% \mathrm{Cl})$ & $0.19(0.12,0.30)$ & $0.03(0.01,0.10)$
\end{tabular}

$\mathrm{Cl}$ confidence interval, AUC area under the curve

$[24,35,39]$ and the Lachman test result $[33,35]$ are important diagnostic criteria for an ACL tear. Further, we have confirmed the importance of trauma (in particular sport-related) for the diagnosis of an ACL tear previously reported by Decary et al. [35], and that when considered individually, a Lachman test may be useful (LR+ between 5 and 10) for diagnosing, and almost conclusive (LR- between <0.1) for excluding an ACL tear when performed by clinicians with advanced orthopaedic training [44].

In contrast to past studies [45, 46], we have identified that increasing age and a family history of an ACL tear, may be important diagnostic criteria for an ACL tear. Interestingly, other variables previously reported to be useful for diagnosis including pivoting mechanism of injury, 'popping' sensation at the time of injury, giving away and anterior drawer or pivot shift test result [24, $35,39,43]$ did not factor into our findings. Reasons for this may include: previous studies smaller sample sizes [24, 34, 39]; differences in sample characteristics (participant age, acuteness and diversity of knee conditions); number of practitioners; practitioner characteristics (profession, experience, degree of confidence in performing and interpreting clinical tests) and; inability to assess specific variables (age, family history, 'popping' sensation or pivoting mechanism of injury) due to insufficient or lack of data availability.

\section{Implications for primary care}

Primary point-of-care practitioners diagnosis ACL tears differently than practitioners with specialized orthopaedic training, relying more heavily on clinical history than a physical examination [24]. This likely reflects the unique challenges that primary care practitioners face in assessing acute knee injuries including an increased likelihood that pain, swelling and muscle guarding will interfere with the physical examination given the close proximity of the examination to the trauma. Varying levels of practitioner confidence in performing special clinical tests such as the Lachman or Pivot Shift test due to less orthopaedic training [47-49], and less exposure to patients with traumatic knee injuries may also be a challenge unique to primary point-of-care practitioners. Embracing these realities is essential to improving the diagnostic accuracy of ACL tears in primary care settings. Although our findings indicate that a combination of patient-reported variables (age, sport-related trauma, immediate swelling, and family history ACL tear) had inferior diagnostic accuracy than when considered alongside the Lachman test, they were capable of identifying 95\% (specificity) of those without an ACL tear. Implementation of this information through the development of a primary point-of-care clinical decision support tool presents a unique opportunity to improve the efficiency of ACL tear diagnosis in primary care settings, while triaging patients to the most appropriate diagnostic (i.e., clinician with advanced orthopaedic training) and/or care pathway (i.e., rehabilitation and/or surgical consultation).

\section{Strengths and limitations}

By leveraging the EMRs of a large, regional sports medicine clinic and multiple clinicians, we were able to investigate diagnostic indicators of ACL tear in the largest sample size reported to date. Despite the large number of records with ACL tears, it is important to acknowledge that this was a retrospective chart review and the data were not collected for the stated purpose. As a result, there were a large number of incomplete EMRs which made it difficult to include variables that others have identified as being helpful in diagnosing an ACL tear such as a 'popping' sensation at the time of injury, a pivot mechanism of injury and Pivot Shift Test result in our multivariable analyses [35]. It is also important to point out that these findings may not be generalizable to other practice settings, and older patients with nonsport related knee injuries. Despite these limitations, this unique real-world dataset provides an understanding of what variables may be most useful for diagnosing an ACL tear in a practice setting with a high prevalence of 
ACL tears and clinicians with orthopaedic training. This information lays the foundation for the development of clinical decision tools for primary point-of-care practitioners.

\section{Future steps}

Beyond delivering two preliminary predictive statistical models, this research has allowed us to explore the quality and completeness of the EMR data, observe clinical processes and foster clinical relationships and collaborations. This information will directly inform a multi-site prospective study aimed at developing, externally validating and assessing the accuracy of a clinical decision support tool for identifying patients with full-thickness ACL tears in primary point-of-care settings. Once developed, this tool will provide a foundation for optimizing the care, development of appropriate clinical pathways, and outcomes of patients with acute knee injuries including an ACL tear.

\section{Conclusions}

A combination of patient-reported and cliniciangenerated variables are superior for detecting a fullthickness ACL tear compared to patient-reported variables alone. Despite this, a high proportion of individuals without an ACL tear can be accurately identified by considering patient-reported age, injury setting, immediate swelling and family history of ACL tear. These findings directly inform future prospective development of a primary point-of-care clinical decision support tool to facilitate timely and accurate ACL tear diagnosis.

\section{Supplementary information}

Supplementary information accompanies this paper at https://doi.org/10 1186/s12891-020-03237-x.

\section{Additional file 1. Included International Classification of Disease 9} Codes.

Additional file 2. Practitioner Survey of Variables Important for ACL Tear Diagnosis.

\begin{abstract}
Abbreviations
ACL: Anterior cruciate ligament; AKIC: Acute knee injury clinic; AUC: Area under the curve; BMl: Body mass index; Cl: Confidence interval; cm: Centimeter; EMR: Electronic medical record; ICD: International Classification of Disease; kg: Kilograms; LR: Likelihood ratio; m: Meter; MRI: Magnetic resonance imaging; OA: Osteoarthritis; OR: Odds ratio; RTS: Return to sport; ROC: Receiver-operating characteristic; SE: Standard error; STARD: Standards for Reporting Diagnostic Accuracy Studies
\end{abstract}

\section{Acknowledgements}

The authors would like to acknowledge the assistance of Sudeepta Aruka and Hilary Short MSc, the support of the Consultation and Research Services Platform at the Alberta SPOR SUPPORT Unit (data management and statistical services), and support of the administrative staff of the Glen Sather Sports Medicine Clinic.

\section{Authors' contributions}

JW and LM conceived and designed the study. JW, LM, MC conducted the study including leading the data identification, data extraction and preliminary analyses. BP and IH provided statistical expertise and performed the analyses. TD, CH, and DO provided input on the study approach and interpretation of the findings of the analyses. MC drafted the first version of the manuscript. JW obtained funding and finalized the manuscript. All authors provided feedback on the manuscript and approved the final submission.

\section{Funding}

This project was partially supported by the Glen Sather Sports Medicine Research Development Fund and Division of Orthopedic Surgery at the University of Alberta. These organizations had no role in the design, conduct, interpretation or reporting of the study.

\section{Availability of data and materials}

The datasets used and/or analysed during the current study are available from the corresponding author on reasonable request.

\section{Ethics approval and consent to participate}

This study was approved by The Health Research Ethics Board - Health Panel at the University of Alberta, Canada (Pro00065514).

\section{Consent for publication}

Not applicable.

\section{Competing interests}

This study was supported by funding from the Glen Sather Sports Medicine Research Development Fund and Division of Orthopedic Surgery at the University of Alberta. The views presented here are solely the responsibility of the authors and do not represent the views of these organizations. The authors report no conflicts of interest.

\section{Author details}

'Department of Physical Therapy, Faculty of Medicine, University of British Columbia, 2177 Westbrook Mall, Vancouver V6T 1Z3, Canada. ${ }^{2}$ Arthritis Research Canada, Richmond, Canada. ${ }^{3}$ Department of Physical Therapy, Faculty of Rehabilitation Medicine, University of Alberta, Edmonton, Canada. ${ }^{4}$ Glen Sather Sports Medicine Clinic, University of Alberta, Edmonton, Canada. ${ }^{5}$ EPICORE Centre \& Alberta SPOR Support Unit, Consultation \& Research Services, University of Alberta, Edmonton, Canada. ${ }^{6}$ Department of Family Medicine, Faculty of Medicine and Dentistry, University of Alberta, Edmonton, Canada. ${ }^{7}$ Department of Surgery, Faculty of Medicine and Dentistry, University of Alberta, Edmonton, Canada. ${ }^{8}$ School of Rehabilitation Science, McMaster University, Hamilton, Canada.

Received: 6 December 2019 Accepted: 25 March 2020

Published online: 17 April 2020

\section{References}

1. Sanders TL, Maradit Kremers H, Bryan AJ, Larson DR, Dahm DL, Levy BA, et al. Incidence of anterior cruciate ligament tears and reconstruction: a 21year population-based study. Am J Sports Med. 2016;44(6):1502-7.

2. Suter LG, Smith SR, Katz JN, Englund M, Hunter DJ, Frobell R, et al. Projecting lifetime risk of symptomatic knee osteoarthritis and Total knee replacement in individuals sustaining a complete anterior cruciate ligament tear in early adulthood. Arthritis Care Res. 2017;69(2):201-8.

3. Arastu MH, Grange S, Twyman R. Prevalence and consequences of delayed diagnosis of anterior cruciate ligament ruptures. Knee Surg Sports Traumatol Arthrosc. 2015;23(4):1201-5.

4. Silvers $\mathrm{HJ}$, Mandelbaum BR. Prevention of anterior cruciate ligament injury in the female athlete. Br J Sports Med. 2007;41 (Suppl 1):i52-9.

5. Louw QA, Manilall J, Grimmer KA. Epidemiology of knee injuries among adolescents: a systematic review. Br J Sports Med. 2008;42(1):2-10.

6. Prodromos CC, Han Y, Rogowski J, Joyce B, Shi K. A meta-analysis of the incidence of anterior cruciate ligament tears as a function of gender, sport, and a knee injury-reduction regimen. Arthroscopy. 2007;23(12):1320-25.e6.

7. Whittaker JL, Woodhouse LJ, Nettel-Aguirre A, Emery CA. Outcomes associated with early post-traumatic osteoarthritis and other negative health consequences 3-10 years following knee joint injury in youth sport. Osteoarthr Cartil. 2015;23(7):1122-9. 
8. Whittaker JL, Toomey CM, Nettel-Aguirre A, Jaremko JL, Doyle-Baker PK, Woodhouse $L$, et al. Health-related outcomes following a youth sportrelated knee injury. Med Sci Sports Exerc. 2018;51(2):255-63.

9. Baltich J, Whittaker J, Von Tscharner V, Nettel-Aguirre A, Nigg BM, Emery C The impact of previous knee injury on force plate and field-based measures of balance. Clin Biomech. 2015;30(8):832-8.

10. Paterno MV, Rauh MJ, Schmitt LC, Ford KR, Hewett TE. Incidence of contralateral and ipsilateral anterior cruciate ligament (ACL) injury after primary ACL reconstruction and return to sport. Clin J Sport Med. 2012; 22(2):116-21.

11. Toomey CM, Whittaker JL, Nettel-Aguirre A, Reimer RA, Woodhouse LJ, Ghali $B$, et al. Higher fat mass is associated with a history of knee injury in youth sport. J Orthop Sports Phys Ther. 2017:47(2):80-7.

12. Ajuied A, Wong F, Smith C, Norris M, Earnshaw P, Back D, et al. Anterior cruciate ligament injury and radiologic progression of knee osteoarthritis: a systematic review and meta-analysis. Am J Sports Med. 2014;42(9):2242-52.

13. Richmond SA, Fukuchi RK, Ezzat A, Schneider K, Schneider G, Emery CA. Are joint injury, sport activity, physical activity, obesity, or occupational activities predictors for osteoarthritis? A systematic review. J Orthop Sports Phys Ther. 2013;43(8):515-B19.

14. Whittaker JL, Toomey CM, Woodhouse LJ, Jaremko JL, Nettel-Aguirre A, Emery CA. Association between MRI-defined osteoarthritis, pain, function and strength 3-10 years following knee joint injury in youth sport. Br J Sports Med. 2018;52(14):934-9.

15. Zadro JR, Pappas E. Time for a different approach to anterior cruciate ligament injuries: educate and create realistic expectations. Sports Med. 2018;49(3):357-63.

16. Filbay SR, Roos EM, Frobell RB, Roemer F, Ranstam J, Lohmander LS. Delaying $A C L$ reconstruction and treating with exercise therapy alone may alter prognostic factors for 5-year outcome: an exploratory analysis of the KANON trial. Br J Sports Med. 2017;51(22):1622-9.

17. Shea KG, Carey JL, Richmond J, Sandmeier R, Pitts RT, Polousky JD, et al. The American Academy of Orthopaedic surgeons evidence-based guideline on management of anterior cruciate ligament injuries. J Bone Joint Surg Am. 2015;97(8):672-4

18. Meuffels DE, Poldervaart MT, Diercks RL, Fievez AW, Patt TW, Hart CP, et al. Guideline on anterior cruciate ligament injury. Acta Orthop. 2012;83(4):379-86.

19. Esmaili Jah AA, Keyhani S, Zarei R, Moghaddam AK. Accuracy of MRI in comparison with clinical and arthroscopic findings in ligamentous and meniscal injuries of the knee. Acta Orthop Belg. 2005;71(2):189-96.

20. Kocabey Y, Tetik O, Isbell WM, Atay OA, Johnson DL. The value of clinical examination versus magnetic resonance imaging in the diagnosis of meniscal tears and anterior cruciate ligament rupture. Arthroscopy. 2004 20(7):696-700

21. Rayan F, Bhonsle S, Shukla DD. Clinical, MRI, and arthroscopic correlation in meniscal and anterior cruciate ligament injuries. Int Orthop. 2009;33(1):129-32.

22. Kopka M, Mohtadi N, Naylor A, Walker R, Donald M, Frank C. The use of magnetic resonance imaging in acute knee injuries can be reduced by nonphysician expert clinics. Physician Sport Med. 2015:43(1):30-6.

23. O'Shea KJ, Murphy KP, Heekin RD, Herzwurm PJ. The diagnostic accuracy of history, physical examination, and radiographs in the evaluation of traumatic knee disorders. Am J Sports Med. 1996;24(2):164-7.

24. Geraets SE, Meuffels DE, van Meer BL, Breedveldt Boer HP, Bierma-Zeinstra SM, Reijman M. Diagnostic value of medical history and physical examination of anterior cruciate ligament injury: comparison between primary care physician and orthopaedic surgeon. Knee Surg Sports Traumatol Arthrosc. 2015:23(4):968-74.

25. Fowler PJ, Regan WD. The patient with symptomatic chronic anterior cruciate ligament insufficiency. Results of minimal arthroscopic surgery and rehabilitation. Am J Sports Med. 1987;15(4):321-5.

26. Guillodo Y, Rannou N, Dubrana F, Lefevre C, Saraux A. Diagnosis of anterior cruciate ligament rupture in an emergency department. J Trauma. 2008;65(5):1078-82.

27. Hartnett N, Tregonning RJ. Delay in diagnosis of anterior cruciate ligament injury in sport. N Z Med J. 2001;114(1124):11-3.

28. Jackson JL, O'Malley PG, Kroenke K. Evaluation of acute knee pain in primary care. Ann Intern Med. 2003;139(7):575-88.

29. Parwaiz $H$, Teo AQ, Servant $C$. Anterior cruciate ligament injury: a persistently difficult diagnosis. Knee. 2016;23(1):116-20.

30. Sanders TL, Kremers HM, Bryan AJ, Fruth KM, Larson DR, Pareek A, et al. Is anterior cruciate ligament reconstruction effective in preventing secondary meniscal tears and osteoarthritis? Am J Sports Med. 2016;44(7):1699-707.
31. Sommerfeldt M, Raheem A, Whittaker J, Hui C, Otto D. Recurrent instability episodes and meniscal or cartilage damage after anterior cruciate ligament injury: a systematic review. Orthop J Sports Med. 2018;6(7): 2325967118786507

32. Bernstein J. Early versus delayed reconstruction of the anterior cruciate ligament: a decision analysis approach. J Bone Joint Surg Am. 2011;93(9): e48.

33. Benjaminse A, Gokeler A, van der Schans CP. Clinical diagnosis of an anterior cruciate ligament rupture: a meta-analysis. J Orthop Sports Phys Ther. 2006;36(5):267-88.

34. Decary S, Ouellet P, Vendittoli PA, Roy JS, Desmeules F. Diagnostic validity of physical examination tests for common knee disorders: an overview of systematic reviews and meta-analysis. Phys Ther Sport. 2017;23:143-55.

35. Decary S, Fallaha M, Belzile S, Martel-Pelletier J, Pelletier JP, Feldman D, et al. Clinical diagnosis of partial or complete anterior cruciate ligament tears using patients' history elements and physical examination tests. PLoS One. 2018;13(6):e0198797.

36. Oberlander MA, Shalvoy RM, Hughston JC. The accuracy of the clinical knee examination documented by arthroscopy. A prospective study. Am J Sports Med. 1993;21(6):773-8.

37. Felli L, Garlaschi G, Muda A, Tagliafico A, Formica M, Zanirato A, et al. Comparison of clinical, MRI and arthroscopic assessments of chronic ACL injuries, meniscal tears and cartilage defects. Musculoskelet Surg. 2016; 100(3):231-8.

38. Rose NE, Gold SM. A comparison of accuracy between clinical examination and magnetic resonance imaging in the diagnosis of meniscal and anterior cruciate ligament tears. Arthroscopy. 1996;12(4):398-405.

39. Wagemakers HP, Luijsterburg PA, Boks SS, Heintjes EM, Berger MY, Verhaar JA, et al. Diagnostic accuracy of history taking and physical examination for assessing anterior cruciate ligament lesions of the knee in primary care. Arch Phys Med Rehabil. 2010;91(9):1452-9.

40. Bossuyt PM, Reitsma JB, Bruns DE, Gatsonis CA, Glasziou PP, Irwig L, et al. STARD 2015: an updated list of essential items for reporting diagnostic accuracy studies. BMJ. 2015;351:h5527.

41. Peduzzi P, Concato J, Kemper E, Holford TR, Feinstein AR. A simulation study of the number of events per variable in logistic regression analysis. J Clin Epidemiol. 1996:49:1373-9.

42. Li K, Du J, Huang LX, Ni L, Liu T, Yang HL. The diagnostic accuracy of magnetic resonance imaging for anterior cruciate ligament injury in comparison to arthroscopy: a meta-analysis. Sci Rep. 2017;7(1):7583.

43. Leblanc MC, Kowalczuk M, Andruszkiewicz N, Simunovic N, Farrokhyar F, Turnbull TL, et al. Diagnostic accuracy of physical examination for anterior knee instability: a systematic review. Knee Surg Sports Traumatol Arthrosc. 2015:23(10):2805-13.

44. Hebert R, Jamtvedt G, Hagen KB, Meed J. Practical Evidence-based Physiotherapy (Second Edition). Second ed. London: Churchill Livingstone; 2011

45. Flynn RK, Pedersen CL, Birmingham TB, Kirkley A, Jackowski D, Fowler PJ. The familial predisposition toward tearing the anterior cruciate ligament: a case control study. Am J Sports Med. 2005:33(1):23-8.

46. Bourke HE, Salmon LJ, Waller A, Patterson V, Pinczewski LA. Survival of the anterior cruciate ligament graft and the contralateral $A C L$ at a minimum of 15 years. Am J Sports Med. 2012;40(9):1985-92.

47. Pinney SJ, Regan WD. Educating medical students about musculoskeletal problems. Are community needs reflected in the curricula of Canadian medical schools? J Bone Joint Surg. 2001;83-a(9):1317-20

48. DiCaprio MR, Covey A, Bernstein J. Curricular requirements for musculoskeletal medicine in American medical schools. T J Bone Joint Surg. 2003:85-a(3):565-7.

49. Freedman KB, Bernstein J. The adequacy of medical school education in musculoskeletal medicine. J Bone Joint Surg. 1998:80(10):1421-7.

\section{Publisher's Note}

Springer Nature remains neutral with regard to jurisdictional claims in published maps and institutional affiliations. 